\title{
Genetic line comparisons and genetic parameters for endoparasite infections and test-day milk production traits
}

\author{
Katharina May, ${ }^{*} \dagger$ Kerstin Brügemann, ${ }^{*}$ Tong Yin, ${ }^{*}$ Carsten Scheper, ${ }^{*}$ Christina Strube, $†$ and Sven König* \\ *Institute of Animal Breeding and Genetics, Justus-Liebig-University of Gießen, 35390 Gießen, Germany \\ †Institute for Parasitology, Centre for Infection Medicine, University of Veterinary Medicine Hannover, 30559 Hannover, Germany
}

\begin{abstract}
Keeping dairy cows in grassland systems relies on detailed analyses of genetic resistance against endoparasite infections, including between- and withinbreed genetic evaluations. The objectives of this study were (1) to compare different Black and White dairy cattle selection lines for endoparasite infections and (2) the estimation of genetic (co)variance components for endoparasite and test-day milk production traits within the Black and White cattle population. A total of 2,006 fecal samples were taken during 2 farm visits in summer and autumn 2015 from 1,166 cows kept in 17 small- and medium-scale organic and conventional German grassland farms. Fecal egg counts were determined for gastrointestinal nematodes (FEC-GIN) and flukes (FEC-FLU), and fecal larvae counts for the bovine lungworm Dictyocaulus viviparus (FLC-DV). The lowest values for gastrointestinal nematode infections were identified for genetic lines adopted to pasturebased production systems, especially selection lines from New Zealand. Heritabilities were low for FECGIN (0.05-0.06 \pm 0.04$)$ and FLC-DV $(0.05 \pm 0.04)$, but moderate for FEC-FLU $(0.33 \pm 0.06)$. Almost identical heritabilities were estimated for different endoparasite trait transformations (log-transformation, square root). The genetic correlation between FEC-GIN and FLC-DV was $1.00 \pm 0.60$, slightly negative between FEC-GIN and FEC-FLU $(-0.10 \pm 0.27)$, and close to zero between FLC-DV and FEC-FLU (0.03 \pm 0.30$)$. Random regression test-day models on a continuous time scale [days in milk (DIM)] were applied to estimate genetic relationships between endoparasite and longitudinal test-day production traits. Genetic correlations were negative between FEC-GIN and milk yield (MY) until DIM 85, and between FEC-FLU and MY until DIM 215. Genetic correlations between FLC-DV and MY were negative throughout lactation, indicating
\end{abstract}

Received March 21, 2017.

Accepted May 17, 2017.

${ }^{1}$ Corresponding author: sven.koenig@agrar.uni-giessen.de improved disease resistance for high-productivity cows. Genetic relationships between FEC-GIN and FECFLU with milk protein content were negative for all DIM. Apart from the very early and very late lactation stage, genetic correlations between FEC-GIN and milk fat content were negative, whereas they were positive for FEC-FLU. Genetic correlations between FEC-GIN and somatic cell score were positive, indicating similar genetic mechanisms for susceptibility to udder and endoparasite infections. The moderate heritabilities for FEC-FLU suggest inclusion of FEC-FLU into overall organic dairy cattle breeding goals to achieve long-term selection response for disease resistance.

Key words: endoparasite trait, test-day production trait, genetic parameter, random regression model

\section{INTRODUCTION}

Endoparasite infections lead to measurable milk production losses in dairy cows, have a detrimental effect on product quality, and cause economic losses in affected herds (Charlier et al., 2005; Holzhauer et al., 2011). Gastrointestinal nematodes (GIN), as well as the bovine lungworm (Dictyocaulus viviparus), negatively affected growth and health of first-season grazing calves (Ploeger and Kloosterman, 1993; Schnieder et al., 1993). In addition, a significant detrimental effect on productivity of older cattle was observed (Charlier et al., 2009). Schunn et al. (2013) reported seroprevalence rates up to $31.2 \%$ for German cattle herds for $D$. viviparus. Infections with the liver fluke Fasciola hepatica in adult cattle were mainly subclinical (Kaplan, 2001); nevertheless, substantial economic loss due to reduced milk production has been reported even for subclinical infections (Knubben-Schweizer et al., 2010). For F. hepatica, Kuerpick et al. (2013) observed seroprevalence rates up to $38.4 \%$ in different German federal states.

In recent years, the percentage of German consumers demanding milk from cows kept in pasture-based production systems is increasing (BÖLW, 2016). As a consequence, and due to other aspects such as high indoor feeding costs and fluctuations of conventional 
milk payment systems, milk from organic or pasturebased production systems is considered as an attractive economic alternative. However, German Holstein cows (GHC), in particular, have been selected for modern and large-scale indoor systems for decades, raising questions of possible genotype $\times$ environment interactions and their adaptation capability to harsh environments (König et al., 2005a). In this regard, in grassland systems dairy cows are exposed to higher infection pressure with endoparasites. A challenge for the farm management in organic farming systems is that medical anthelminthic treatments for adult cattle are strongly restricted. Moreover, an increasing resistance of sheep and cattle nematodes against anthelmintics has been observed (Bisset, 1994; Moll et al., 2000; McMahon et al., 2013).

Application of breeding instruments and targeted selection of cattle or of cattle breeds with enhanced resistance against specific pathogens (i.e., gastrointestinal nematodes) was suggested by Morris et al. (1997). Several studies identified phenotypic variations of host resistances among cattle breeds from non-European countries for gastrointestinal nematode infections (Suarez et al., 1990, 1995; Peña et al., 2000; Oliveira et al., 2009); however, those study designs mostly addressed comparisons between Bos indicus and Bos taurus purebreds or crossbreds under (sub)tropical conditions. Within cattle breeds, endoparasite resistance was compared among specific sire lines (Seifert, 1977; Kloosterman et al., 1978; Barlow and Piper, 1985). Within-breed selection implies availability of genetic parameters for endoparasite resistance, and ongoing genetic evaluations. Heritability estimates in cattle for different gastrointestinal nematode species were low to moderate (reviewed in Table 1), in a range from 0.04 to 0.36 (Barlow and Piper, 1985; Burrow, 2001). For the susceptibility to liver fluke, McClure et al. (2014) reported a heritability of 0.15 for dairy cattle in Ireland. Moreover, infections and reinfections with the bovine lungworm are of economic importance in dairy cattle herds (Holzhauer et al., 2011; Dank et al., 2015), but not addressed in quantitative-genetic studies.

Genetic correlations between gastrointestinal nematode resistances or fecal egg counts with production parameters (e.g., growth, weight gain) in sheep and beef cattle populations were estimated in various previous studies (Bisset et al., 1992; Gray, 1997; Bouix et al., 1998; Eady et al., 1998; Bishop et al., 2004; Silva et al., 2012). Including milk production traits, genetic correlations were -0.21 between milk yield and fecal nematode egg count, and -0.17 between fat plus protein yield and fecal nematode egg count for Saanen goats in New Zealand (NZL; Morris et al., 1997). In contrast, with a focus on gastrointestinal worm egg counts in crossbred ewes, Afolayan et al. (2009) found a slightly positive but unfavorable genetic correlation (0.08) with milk yield and a moderate genetic relationship (0.42) with protein percentage.

To our knowledge, a substantial gap exists addressing (1) genetic associations between endoparasite infections with production traits in dairy and dual-purpose cattle populations and (2) selection strategies for improved endoparasite resistances. Selection and breeding of appropriate genetic lines within the Black and White dairy and dual-purpose cattle population being best adapted to grazing systems might be one possible breeding strategy. During recent decades, breeding organizations in NZL strongly focused on such alternative breeding strategies (i.e., breeding cattle lines for grazing systems by including alternative functional traits into overall breeding goals; Miglior et al., 2005). In terms of economic efficiency, productivity per hectare of grassland and reproduction performance, Holstein Friesian (HF) cows from NZL were superior over other cattle breeds or lines in pasture-based production systems in Ireland and Switzerland (McCarthy et al., 2007; Piccand et al., 2013).

The objectives of the present study were 2 -fold. First, we used a selection line comparison for endoparasite infections including different Black and White selection

Table 1. Heritability estimates from literature for fecal egg counts of gastrointestinal nematodes (GIN) in cattle

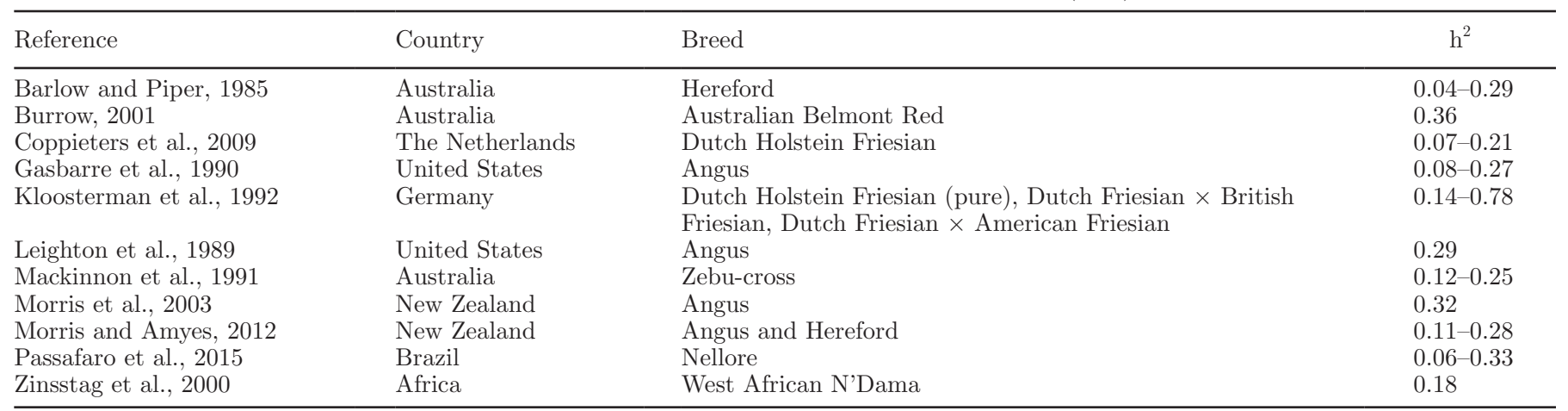


lines based on an established cross-classified research design. Second, we estimated genetic (co)variance components for endoparasite infections and productivity in the Black and White cattle population including all selection lines simultaneously via the full genetic relationship matrix.

\section{MATERIALS AND METHODS}

\section{Research Design}

A pasture genetics project was established in pasture-based production systems in northwest Germany in 2007 to compare the effect of different sire origins on productivity and functional traits. The present study was incorporated in the framework of the pasture genetics project and considered 17 farms (13 organic, 4 conventional) with a strong focus on milking cow grazing $(>8 \mathrm{~h} / \mathrm{d})$. The grassland farms were located in 4 federal states in northwest Germany. Herd sizes ranged from 19 to 215 milking cows, with an average of 72 cows per farm. Requirements for herd selection were (1) no treatments with anthelmintics in the sampling year and (2) access to pasture before June 1. In addition, all farms agreed to use a specific, but randomized mating scheme; that is, the insemination of defined proportions of GHC with Holstein sires from NZL, and with German Holstein (GH) pasture sires from Germany. Those GH pasture sires, which are suited to grazing conditions, represented bulls of German origin with outstanding breeding values for the traits being important in NZL (i.e., small body size, high fat percentage, low SCS, high nonreturn rate, short interval from calving to first insemination). A third genetic line in all herds included female offspring from matings of $\mathrm{GHC}$ with GH HF bulls representing the conventional selection strategy for indoor systems, with a strong focus on breeding values for milk yield (GH milk sires). For matings, farmers were encouraged to use GH milk sires with at least 1 breeding value standard deviation above the population mean $(\sim 500 \mathrm{~kg}$ for milk yield). Milk yield breeding values for GH milk sires ranged from 146 to $1,841 \mathrm{~kg}$, and from -485 to $1,076 \mathrm{~kg}$ for $\mathrm{GH}$ pasture sires (database for national genetic evaluations from August 2016). Hence, the following 3 genetic lines were established and included in the present study: GHC $\times$ NZL sires (HF-NZL; 72 cows), GHC $\times$ GH milk sires (HF-GHm; 639 cows), and GHC $\times$ GH pasture sires (HF-GHp; 70 cows). A fourth genetic line included local Black and White dual-purpose cows of the Deutsche Schwarzbunte Niederungsrind (DSN; 363 cows), the founder of the current German Holstein population. All 4 lines were genetically related among each other, with the lowest relationship coefficient of $0.6 \%$ between DSN and HF-GHm. The research design was cross-classified (several genetic lines per herd). A remaining set of 22 herd contemporaries was assigned to the category mixed breed (MIX), including GH $\times$ Jersey and Angler $\mathrm{F}_{1}$ crossbreds, and $\mathrm{F}_{1}$ crossbreds between $\mathrm{GH}$ with dual-purpose Fleckvieh.

\section{Data}

Test-Day Production Traits. Test-day data for all 1,166 cows included repeated measurements for the production traits milk yield (MY), protein percentage (Pro\%), fat percentage (Fat\%), fat-to-protein ratio (FPR), and SCC. Somatic cell counts were $\log$ transformed into $\mathrm{SCS}=\log _{2}(\mathrm{SCC} / 100.000)+3$ (Ali and Shook, 1980). Lactation number ranged from 1 to 11 with a mean of $2.7 ; 26.1 \%$ of all records were from the first lactation, $27.2 \%$ from the second lactation, $17.3 \%$ from the third lactation, $12.2 \%$ from the fourth lactation, and $17.2 \%$ from later lactations. Cows with less than 5 test-day records were excluded from the analysis. Descriptive statistics for the test-day production traits are given in Table 2.

Endoparasite Traits. In total, 2,006 fecal samples were collected during 2 farm visits (June-July 2015 and September-October 2015) from the 1,166 dairy cows, including repeated measurements for 840 cows. Fecal larvae counts for the bovine lungworm $D$. viviparus (FLC-DV) were detected with the Baermann technique (Baermann, 1917) using $40 \mathrm{~g}$ of feces per cow. Fecal egg counts per gram of feces for GIN (FEC-GIN) were determined by a modified McMaster technique, according to Thienpont et al. (1979), with a sensitivity of 25 eggs/g of feces (EPG). Sedimentation technique with $10 \mathrm{~g}$ of feces per cow was used to detect eggs of flukes. The liver fluke $F$. hepatica and the rumen

Table 2. Descriptive statistics for test-day production traits

\begin{tabular}{lcrrrr}
\hline Trait & Number of test-day records & Mean & SD & Minimum & Maximum \\
\hline Milk yield (kg) & 10,132 & 22.06 & 6.97 & 2.20 & 57.20 \\
Protein content (\%) & 10,125 & 3.37 & 0.38 & 2.38 & 6.32 \\
Fat content (\%) & 10,125 & 4.30 & 0.72 & 1.75 & 9.09 \\
Fat-to-protein ratio & 10,125 & 1.28 & 0.19 & 0.40 & 3.29 \\
SCS & 10,115 & 3.02 & 1.64 & 0.01 & 10.01 \\
\hline
\end{tabular}


Table 3. Total number of fecal samples and prevalence rates [number (no.) and \% of positive samples (\%)] for Dictyocaulus viviparus, gastrointestinal nematodes (GIN), and flukes in summer, autumn, and in both sampling periods (summer + autumn)

\begin{tabular}{|c|c|c|c|c|c|c|c|c|c|}
\hline \multirow[b]{3}{*}{ Item } & \multicolumn{3}{|c|}{ D. viviparus } & \multicolumn{3}{|c|}{ GIN } & \multicolumn{3}{|c|}{ Flukes } \\
\hline & \multirow[b]{2}{*}{ Total } & \multicolumn{2}{|c|}{ Prevalence } & \multirow[b]{2}{*}{ Total } & \multicolumn{2}{|c|}{ Prevalence } & \multirow[b]{2}{*}{ Total } & \multicolumn{2}{|c|}{ Prevalence } \\
\hline & & No. & $\%$ & & No. & $\%$ & & No. & $\%$ \\
\hline Summer $^{1}$ & 960 & 7 & 0.7 & 961 & 320 & 33.3 & 963 & 97 & 10.1 \\
\hline Autumn ${ }^{2}$ & 1,028 & 35 & 3.4 & 1,036 & 242 & 23.4 & 1,043 & 96 & 9.2 \\
\hline Summer + autumn & 1,988 & 42 & 2.1 & 1,997 & 562 & 28.1 & 2,006 & 193 & 9.6 \\
\hline
\end{tabular}

${ }^{1}$ Time span between June 29 and July 31.

${ }^{2}$ Time span between September 1 and October 5.

fluke Paramphistomum spp./Calicophoron spp. were detected, and the sum of counts from both species was defined as the trait fecal egg count for flukes (FECFLU). The maximal value was 46 for FLC-DV, 225 for FEC-GIN, and 89 for FEC-FLU. Prevalence rates for all 3 endoparasite traits for the different sampling periods are given in Table 3. For GIN and flukes higher prevalence rates were found during the summer month, but for $D$. viviparus prevalences were larger in autumn.

To achieve a Gaussian-like distribution of traits, endoparasite larvae and egg counts (FLC-DV, FECGIN, and FEC-FLU) were log-transformed with $\log _{\mathrm{E}}$ (untransformed endoparasite trait +100$)$ (LogFLC-DV, LogFEC-GIN, and LogFEC-FLU, respectively), and square roots of untransformed endoparasite traits were computed (SqrtFLC-DV, SqrtFEC-GIN, and SqrtFEC-FLU, respectively). However, all trait definitions did not follow a Gaussian distribution (based on the results from the Shapiro-wilk test). Furthermore, endoparasite traits were defined as binary data for D. viviparus (BinFLC-DV), for gastrointestinal nematodes (BinFEC-GIN), and for flukes (BinFEC-FLU). The threshold for a cow to be defined as infected was 25 EPG for FEC-GIN, 1 egg/10 $\mathrm{g}$ of feces for FEC-FLU, and 1 larva/40 $\mathrm{g}$ of feces for FLC-DV. Infected cows received a score of 1 ; otherwise a score of 0 was assigned. Descriptive statistics for all endoparasite trait definitions are given in Table 4.

\section{Statistical Models}

Genetic Line Comparisons. Analyses of variance and estimation of least squares means (LSM) were carried out using the statistical software SAS version 9.4 (SAS Institute; Cary, NC). For the endoparasite traits FLC-DV, FEC-GIN, and FEC-FLU, the following linear mixed model (model 1; PROC MIXED) was applied:

$$
\begin{gathered}
\mathrm{y}_{\mathrm{ijklmn}}=\mu+\text { Farm }_{\mathrm{i}}+\text { Lstage }_{\mathrm{j}}+\text { Parity }_{\mathrm{k}} \\
+\mathrm{GL}_{\mathrm{l}}\left(\mathrm{sp}_{\mathrm{m}}\right)+\text { Cow }_{\mathrm{n}}+\mathrm{e}_{\mathrm{ijklmn}},
\end{gathered}
$$

where $\mathrm{y}_{\mathrm{ijklmn}}=$ observations for FLC-DV, FEC-GIN, and FEC-FLU; $\mu=$ overall mean effect; Farm $_{\mathrm{i}}=$ fixed effect of the ith farm $(1, \ldots, 17) ;$ Lstage $_{j}=$ fixed ef-

Table 4. Descriptive statistics for endoparasite traits

\begin{tabular}{lcccccc}
\hline Endoparasite trait $^{1}$ & No. of observations & No. of cows & Mean & SD & Minimum & Maximum \\
\hline FLC-DV & 1,988 & 1,163 & 0.17 & 2.14 & 0 & 46.0 \\
LogFLC-DV & 1,988 & 1,163 & 4.61 & 0.02 & 4.61 & 6.78 \\
SqrtFLC-DV & 1,988 & 1,163 & 1.72 & 0.41 & 0 & 4.98 \\
BinFLC-DV & 1,988 & 1,163 & 0.02 & & 0 & 1.00 \\
FEC-GIN & 1,997 & 1,166 & 11.35 & 22.57 & 0 & 225.0 \\
LogFEC-GIN & 1,997 & 1,166 & 4.70 & 0.17 & 4.61 & 15.0 \\
SqrtFEC-GIN & 1,997 & 1,166 & 0.05 & 2.90 & 0 & 5.78 \\
BinFEC-GIN & 1,997 & 1,166 & 0.28 & & 0 & 1.00 \\
FEC-FLU & 2,006 & 1,166 & 0.63 & 3.70 & 0 & 89.0 \\
LogFEC-FLU & 2,006 & 1,166 & 4.61 & 0.03 & 4.61 & 9.43 \\
SqrtFEC-FLU & 2,006 & 1,166 & 0.21 & 0.76 & 0 & 5.24 \\
BinFEC-FLU & 2,006 & 1,166 & 0.10 & & 0 & 1.00
\end{tabular}

${ }^{1}$ FLC-DV = fecal larvae count for Dictyocaulus viviparus; FEC-GIN $=$ fecal egg count for gastrointestinal nematodes; FEC-FLU = fecal egg count for flukes; LogFLC and LogFEC = log-transformed endoparasite fecal larvae and egg counts; SqrtFLC and SqrtFEC = square rooted endoparasite fecal larvae and egg counts; BinFLC and BinFEC = infection status (positive or negative) for the 3 endoparasites. 
fect of the jth lactation stage according to Huth (1995; $\leq 14,14-77,78-140,141-231$, and $\geq 232$ DIM); Parity $=$ fixed effect of the kth parity number $(1,2,3,4$, and $>4) ; \mathrm{GL}_{1}\left(\mathrm{sp}_{\mathrm{m}}\right)=$ fixed effect of the lth genetic line (HF-NZL, HF-GHm, HF-GHp, DSN, and MIX) crossed with the mth sampling period sp $(1,2) ; \mathrm{Cow}_{\mathrm{n}}=$ random effect of the nth cow accounting for the 2 repeated measurements per cow; and $\mathrm{e}_{\mathrm{ijklmn}}=$ random residual effect.

Analyses of variance for the binary endoparasite traits (BinFLC-DV, BinFEC-GIN, and BinFEC-FLU) were conducted by applying generalized linear mixed models (model 2) with a logit link function, as implemented in the GLIMMIX procedure of SAS version 9.4:

$$
\begin{gathered}
\operatorname{logit}\left(\pi_{\text {rstuvw }}\right)=\log \left[\pi_{\text {rstuvw }} /\left(1-\pi_{\text {rstuvw }}\right)\right]=\varphi+\text { Farm }_{\mathrm{r}} \\
+ \text { Lstage }_{\mathrm{s}}+\text { Parity }_{\mathrm{t}}+\mathrm{GL}_{\mathrm{u}}\left(\mathrm{sp}_{\mathrm{v}}\right)+\text { Cow }_{\mathrm{w}},
\end{gathered}
$$

where $\pi_{\text {rstuvw }}$ was the probability for a cow to be positive for endoparasite infections; $\varphi$ was the overall mean effect; Farm ${ }_{\mathrm{r}}$, Lstage , Parity $_{\mathrm{t}}$, and $\mathrm{GL}_{\mathrm{u}}$ crossed with the sampling period $\mathrm{sp}_{\mathrm{v}}$ were fixed effects as defined in model [1]; and $\mathrm{Cow}_{\mathrm{w}}$ was the random cow effect accounting for the 2 repeated measurements.

Estimation of Genetic Parameters. Estimations of genetic (co)variance components for endoparasite and test-day production traits were conducted by applying the software package DMU (Madsen and Jensen, 2013) and using the AI-REML algorithm for animal models. For quantitative genetic analyses, all 4 Black and White selection lines (i.e., HF-NZL, HF-GHm, HF-GHp, and DSN) were considered simultaneously via the full additive genetic relationship matrix. Due to the different selection line strategies, consideration of genetic group effects or modeling of phantom parent groups might be a further alternative. Nevertheless, the same grand sires were identified in the $3 \mathrm{HF}$ lines. In consequence, the cows from the different Black and White selection lines are also not separated in official national genetic evaluations.

Standard errors for heritabilities were calculated by using R (version 3.3.0, R Core Team, 2013), and applying a Taylor series expansion as reported by Fischer et al. (2004). Standard errors for genetic correlations were calculated as suggested by Lynch and Walsh (1998). Standard errors of phenotypic correlations between endoparasite traits were approximated considering the variances of (co)variance estimates for genetic, permanent environmental, and residual effects, and applying the delta-method as implemented in the $\mathrm{R}$ package msm (Jackson, 2016).

For genetic analyses of repeated measured endoparasite traits (FLC-DV, LogFLC-DV, SqrtFLC-DV,
FEC-GIN，LogFEC-GIN，SqrtFEC-GIN，FEC-FLU, LogFEC-FLU, and SqrtFEC-FLU), the following repeatability model (RM; model 3) was defined:

$$
\begin{aligned}
\mathrm{y}_{\mathrm{ijklmn}}=\mu & + \text { Farm }_{\mathrm{i}}+\text { Lstage }_{\mathrm{j}}+\text { Parity }_{\mathrm{k}}+\mathrm{sp}_{\mathrm{l}} \\
& +\mathrm{AG}_{\mathrm{m}}+\mathrm{pe}_{\mathrm{n}}+\mathrm{e}_{\mathrm{ijklmn}},
\end{aligned}
$$

where $\mathrm{y}_{\mathrm{ijklmn}}=$ observations for FLC-DV, FEC-GIN, and FEC-FLU; $\mu=$ overall mean effect; Farm $_{\mathrm{i}}=$ fixed effect of the ith farm $(1, \ldots, 17)$; Lstage $_{j}=$ fixed effect of the jth lactation stage according to Huth (1995 ; $<14,14-77,78-140,141-231$, and $\geq 232$ DIM); Parity $_{\mathrm{k}}$ $=$ fixed effect of the kth parity number $(1,2,3$, 4, and $>4) ; \mathrm{sp}_{1}=$ fixed effect of the lth sampling period (1, 2); $\mathrm{AG}_{\mathrm{m}}=$ random additive genetic effect of the mth animal in the pedigree data set; $\mathrm{pe}_{\mathrm{n}}=$ random effect for the permanent environment of the nth cow accounting for the 2 repeated measurements per cow; and $\mathrm{e}_{\mathrm{ijk} k \mathrm{mn}}=$ random residual effect.

A random regression test-day model (RRTDM) with DIM as time covariate was applied to estimate genetic parameters for the test-day production traits (MY, Pro\%, Fat\%, FPR, and SCS) in the course of lactation. The RRTDM (model 4) followed the notation by Bohmanova et al. (2008), and was defined as

$$
\begin{gathered}
\mathrm{y}_{\mathrm{ijklmnop}}=\mathrm{HTD}_{\mathrm{i}}+\operatorname{Parity}_{\mathrm{j}}+\mathrm{TS}_{\mathrm{k}}+\mathrm{YS}_{\mathrm{l}}+\sum_{\mathrm{n}=1}^{q} \alpha_{\mathrm{n}} \mathbf{z}_{\mathrm{n}}(s)+ \\
\sum_{\mathrm{n}=1}^{q} \beta_{\mathrm{mn}} \mathbf{z}_{\mathrm{n}}(s)+\sum_{\mathrm{n}=1}^{q} \gamma_{\mathrm{mn}} \mathbf{z}_{\mathrm{n}}(s)+\mathrm{e}_{\mathrm{ijklmnop}}
\end{gathered}
$$

where $y_{\mathrm{ijk} k m n o p}=$ pth test-day record of the mth cow for MY, Pro\%, Fat\%, FPR, and SCS; $\mathrm{HTD}_{\mathrm{i}}=$ fixed effect of the ith herd-test-date; Parity ${ }_{j}=$ fixed effect of $j$ th parity number $(1,2,3,4$, and $>4) ; \mathrm{TS}_{\mathrm{k}}=$ fixed effect of kth time span between each test-day record and the endoparasite sampling date $(\leq-200,>-200$; and $\leq-100$, $>-100$; and $\leq 0,>0$; and $\leq 100,>100) ; \mathrm{YS}_{1}=$ fixed effect of lth year-season of last calving (spring, summer, autumn, and winter within each year); $q=$ the number of covariates (Legendre polynomials of order 2, implying $q=3) ; \alpha_{\mathrm{n}}=$ nth fixed regression coefficient by DIM; $\beta_{\mathrm{mn}}=$ nth random regression coefficient for the additive genetic effect of cow $\mathrm{m}$ by DIM; $\gamma_{\mathrm{mn}}=$ nth random regression coefficient for the permanent environmental effect of cow $\mathrm{m}$ by DIM; $\mathbf{z}(s)=$ vector of covariates of size $q$ (modeled with Legendre polynomials of order 2 ) describing the shape of the lactation curve of fixed and random regressions evaluated at $s$ DIM; and $\mathrm{e}_{\mathrm{ijklmnop}}$ = random residual effect. Model [3] was applied to estimate genetic correlations among endoparasite traits 
in bivariate runs. For the bivariate runs, the following trait combinations ( 2 traits at a time) were considered. First, the combinations of the untransformed endoparasite traits (FLC-DV, FEC-GIN, and FEC-FLU); second, the combination of log-transformed endoparasite traits (LogFLC-DV, LogFEC-GIN, and LogFECFLU); and, third, the combination of square rooted endoparasite traits (SqrtFLC-DV, SqrtFEC-GIN, and SqrtFEC-FLU).

Genetic correlations between endoparasite traits and test-day traits were inferred by applying models [3] (for the endoparasite traits FLC-DV, FEC-GIN, and FECFLU) and [4] (for the longitudinal test-day traits MY, Pro\%, Fat\%, FPR, and SCS).

The (co)variance structure for random effects in bivariate $\mathrm{RM}[3]$ was

$$
\operatorname{var}\left[\begin{array}{c}
\mathbf{a}_{\mathbf{1}} \\
\mathbf{a}_{\mathbf{2}} \\
\mathbf{p e}_{\mathbf{1}} \\
\mathbf{p e}_{\mathbf{2}} \\
\mathbf{e}_{\mathbf{1}} \\
\mathbf{e}_{2}
\end{array}\right]=\left[\begin{array}{cccccc}
\mathrm{g}_{11} \mathbf{A} & \mathrm{g}_{12} \mathbf{A} & 0 & 0 & 0 & 0 \\
\mathrm{~g}_{12} \mathbf{A} & \mathrm{g}_{22} \mathbf{A} & 0 & 0 & 0 & 0 \\
0 & 0 & \mathrm{pe}_{11} \mathbf{I}_{\mathrm{pe}} & \mathrm{pe}_{12} \mathbf{I}_{\mathrm{pe}} & 0 & 0 \\
0 & 0 & \mathrm{pe}_{12} \mathbf{I}_{\mathrm{pe}} & \mathrm{pe}_{22} \mathbf{I}_{\mathrm{pe}} & 0 & 0 \\
0 & 0 & 0 & 0 & \mathrm{r}_{11} \mathbf{I}_{\mathrm{n}} & \mathrm{r}_{12} \mathbf{I}_{\mathrm{n}} \\
0 & 0 & 0 & 0 & \mathrm{r}_{12} \mathbf{I}_{\mathrm{n}} & \mathrm{r}_{22} \mathbf{I}_{\mathrm{n}}
\end{array}\right],
$$

where $\mathbf{a}_{1}$ and $\mathbf{a}_{2}$ were vectors for additive-genetic effects for both traits, $\mathbf{p e}_{1}$ and $\mathbf{p e}_{2}$ were vectors for permanent environmental effects for both traits, $\mathbf{e}_{1}$ and $\mathbf{e}_{2}$ were vectors for residual effects for both traits; $\mathrm{g}_{11}, \mathrm{~g}_{12}$, and $\mathrm{g}_{22}=$ additive genetic (co)variances for endoparasite traits; A was an additive genetic relationship matrix; $\mathrm{pe}_{11}, \mathrm{pe}_{12}$ and $\mathrm{pe}_{22}=$ permanent environmental (co) variances for endoparasite traits; $\mathrm{r}_{11}, \mathrm{r}_{12}$, and $\mathrm{r}_{22}=$ residual (co)variances for endoparasite traits; $\mathbf{I}_{\mathrm{pe}}$ and $\mathbf{I}_{\mathrm{n}}$ were identity matrices for pe cows and $\mathrm{n}$ observations, respectively.

The (co)variance structure for random effects in bivariate models including the RM for endoparasite traits (3) and the RRTDM (4) for test-day production traits was

$\operatorname{var}\left[\begin{array}{c}\mathbf{a}_{1} \\ \mathbf{a}_{2} \\ \mathbf{p e}_{\mathbf{1}} \\ \mathbf{p e}_{2} \\ \mathbf{e}_{\mathbf{1}} \\ \mathbf{e}_{\mathbf{2}}\end{array}\right]=\left[\begin{array}{cccccc}\mathbf{G}_{11} \otimes \mathbf{A} & \mathbf{G}_{12} \otimes \mathbf{A} & 0 & 0 & 0 & 0 \\ \mathbf{G}_{\mathbf{2 1}} \otimes \mathbf{A} & \mathrm{G}_{22} \mathbf{A} & 0 & 0 & 0 & 0 \\ 0 & 0 & \mathbf{P E}_{11} \otimes \mathbf{I}_{\mathrm{pe}} & \mathbf{P E}_{12} \otimes \mathbf{I}_{\mathrm{pe}} & 0 & 0 \\ 0 & 0 & \mathbf{P E}_{21} \otimes \mathbf{I}_{\mathrm{pe}} & \mathrm{PE}_{22} \mathbf{I}_{\mathrm{pe}} & 0 & 0 \\ 0 & 0 & 0 & 0 & \mathrm{R}_{11} \mathbf{I}_{\mathrm{n}} & \mathrm{R}_{12} \mathbf{I}_{\mathrm{n}} \\ 0 & 0 & 0 & 0 & \mathrm{R}_{21} \mathbf{I}_{\mathrm{n}} & \mathrm{R}_{22} \mathbf{I}_{\mathrm{n}}\end{array}\right]$,

where $\mathbf{G}_{11}=3 \times 3$ (co)variance matrix of random regression coefficients for the additive genetic effects for test-day traits; $\mathbf{A}$ was an additive genetic relationship matrix; $\mathbf{G}_{12}, \mathbf{G}_{21}=$ additive genetic covariance matrix between endoparasite and test-day traits; $\mathrm{G}_{22}$
$=$ additive genetic variance for endoparasite traits; $\mathbf{P E}_{11}=3 \times 3$ (co)variance matrix of random regression coefficients for permanent environmental effects for test-day traits; $\mathbf{P} \mathbf{E}_{12}, \mathbf{P E}_{21}=$ covariance matrix for permanent environmental effects between test-day and endoparasite traits; $\mathrm{PE}_{22}=$ variance for permanent environmental effects for endoparasite traits; $R_{11}=$ residual variances for test-day traits; $R_{12}, R_{21}=$ residual covariances between endoparasite and test-day traits; and $R_{22}=$ residual variances for endoparasite traits; $\mathbf{I}_{\mathrm{pe}}$ and $\mathbf{I}_{\mathrm{n}}$ were identity matrices for pe cows and $\mathrm{n}$ observations, respectively.

\section{RESULTS}

\section{Genetic Line Comparisons}

Results for the test of significance for fixed effects (sum of squares type III) as included in model [1] are given in Table 5 . The genetic line effect significantly influenced FLC-DV $(P \leq 0.05)$ and FEC-GIN $(P<$ $0.0001)$, but was not significant $(P>0.05)$ for FECFLU. For FLC-DV in autumn, LSM were significantly higher for DSN compared with HF-GHm (differences of $\mathrm{LSM}=0.54 ; P \leq 0.05$ ). In summer, LSM for FLC-DV in HF-NZL and HF-GHp were quite similar [i.e., differences of LSM (0.01) were not significant $(P>0.05)]$. For the contrast of both grassland lines with HF-GHm, differences of LSM were 0.04 for HF-GHm-HF-NZL, and 0.05 for HF-GHm-HF-GHp $(P>0.05)$. The same trends of genetic line comparisons for FLC-DV were observed in autumn.

Least squares means for FEC-GIN within genetic lines (1) in summer and autumn are shown in Figure 1. Line comparisons in summer were in agreement with results from autumn. For FEC-GIN, LSM decreased from the first (June-July) to the second (SeptemberOctober) sampling period. Lowest values for FEC-GIN were identified for pasture lines HF-NZL and HF-GHp. For HF-NZL, the LSM for FEC-GIN was 5.0 EPG in summer and 11.4 EPG in autumn. In the first sampling period, FEC-GIN with 18.0 EPG was largest in

Table 5. Significance ( $P$-value) of fixed effects on endoparasite traits

\begin{tabular}{lccc}
\hline & \multicolumn{3}{c}{ Endoparasite trait } \\
\cline { 2 - 4 } Fixed effect & FLC-DV & FEC-GIN & \multirow{2}{*}{ FEC-FLU } \\
\hline Genetic line & 0.0057 & 0.0001 & 0.1221 \\
Farm & 0.5240 & 0.0001 & 0.0001 \\
Parity & 0.0001 & 0.0001 & 0.0287 \\
Lactation stage & 0.0012 & 0.0001 & 0.2117 \\
\hline
\end{tabular}

${ }^{1} \mathrm{FLC}-\mathrm{DV}=$ fecal larvae count for Dictyocaulus viviparus; FEC-GIN = fecal egg count for gastrointestinal nematodes; FEC-FLU = fecal egg count for flukes. 


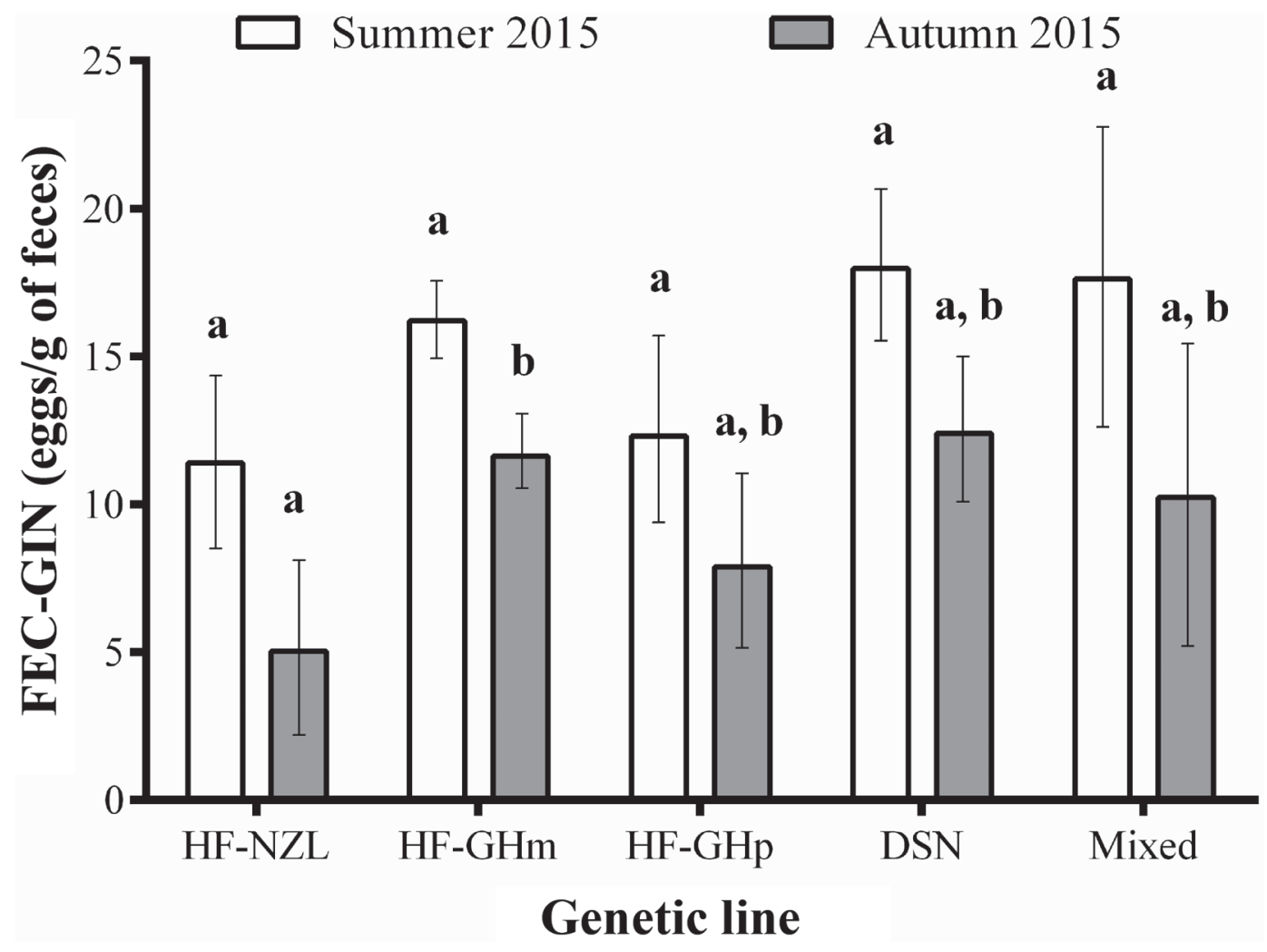

Figure 1. Least squares means [model (1)] with corresponding SE for gastrointestinal nematode egg counts (FEC-GIN) within genetic lines for different sampling periods (summer and autumn 2015). Different letters (a,b) within sampling periods indicate significant differences $(P<$ $0.05)$. HF-NZL $=$ German Holstein cow $($ GHC) $\times$ New Zealand (NZL) sires; HF-GHm $=$ GHC $\times$ German Holstein milk sires; HF-GHp $=$ GHC $\times$ German Holstein pasture sires; DSN $=$ Black and White dual-purpose cows (Deutsche Schwarzbuntes Niederungsrind); mixed $=$ crossbreds between German Holstein $\times$ beef cattle, Jersey, or Angler.

DSN cows, followed by MIX (17.6 EPG) and HF-GHm (16.2 EPG). Interestingly, similar FEC-GIN levels were identified for DSN cows and high-yielding Holsteins (HF-GHm). A significant difference $(P \leq 0.05)$ in autumn was observed when comparing FEC-GIN from HF-GHm and HF-NZL, with larger values for HF-GHm (differences of LSM $=6.60$ ).

The highest GIN egg excretion was identified in first-parity cows in the early lactation stage (Figure 2). Least squares means for FEC-GIN were significantly higher for cows in parity 1 compared with cows in parity $3(P \leq 0.05)$ and $4(P<0.0001)$. Cows in lactation stage $1(<14$ DIM) showed a significantly higher LSM for FEC-GIN compared with cows in lactation stage 2 $(P \leq 0.001 ; 14-77$ DIM $), 3$ ( $P \leq 0.05 ; 78-140$ DIM $), 4$ $(P<0.0001 ; 141-231 \mathrm{DIM})$, and $5(P<0.0001 ; \geq 232$ DIM).

With regard to the binary endoparasite trait definitions [model 2], line comparisons for BinFEC-GIN were in agreement with the results from model [1] for the untransformed trait FEC-GIN. The lowest probability for a GIN infection in summer was identified for the pasture genetic lines HF-NZL (27.3\%) and HF-GHp (25.4\%).
The DSN cattle showed the highest infection rate for GIN (42.2\%), whereas prevalences were slightly lower for HF-GHm (32.3\%) and MIX (30.4\%). Differences for infection rates in different lines in the summer period were not significant $(P>0.05)$. In autumn, prevalences for a GIN infection were significantly lower $(P \leq 0.05)$ in the HF-NZL line (10.4\%) compared with HF-GHm $(24.4 \%)$ and DSN $(26.2 \%)$. Also, for the binary trait definition, infection probability for GIN decreased with increasing parity number. In agreement with results from the linear mixed model [1], highest GIN infection rates (35.9 and $24.8 \%$, respectively) were observed in the first $(<14$ DIM) and in the third (78-140 DIM) lactation stage, whereas infection rates $(19.9 \%)$ were lowest in the last lactation stage ( $\geq 232$ DIM).

\section{Genetic Parameters for Endoparasite Traits}

Heritabilities. Heritability estimates from the bivariate models including all endoparasite trait definitions [i.e., for untransformed (FLC-DV, FEC-GIN, FEC-FLU), log-transformed (LogFLC-DV, LogFECGIN, LogFEC-FLU,) and square-rooted data (Sqrt- 
A

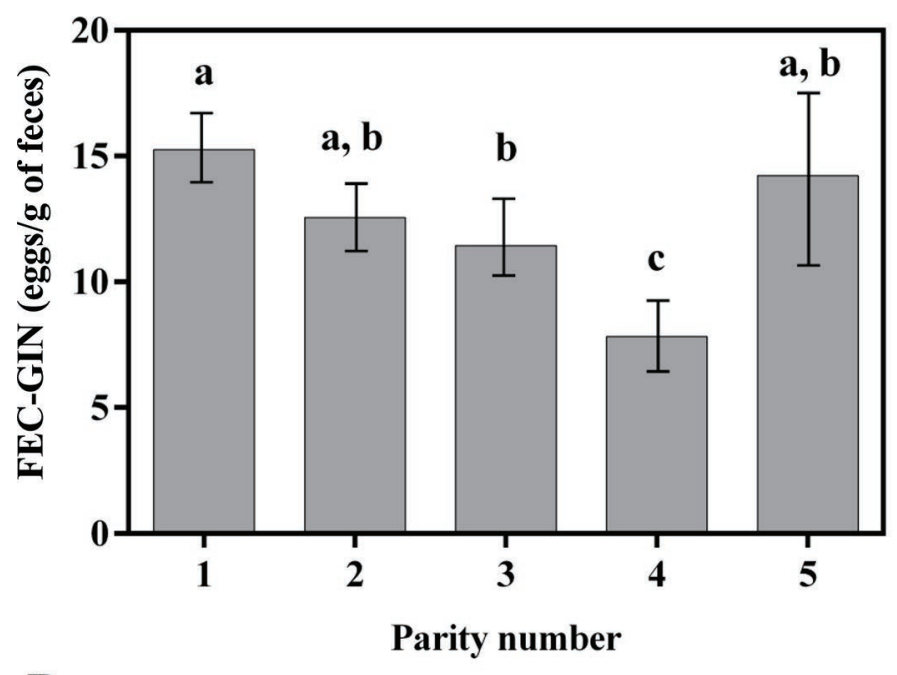

B

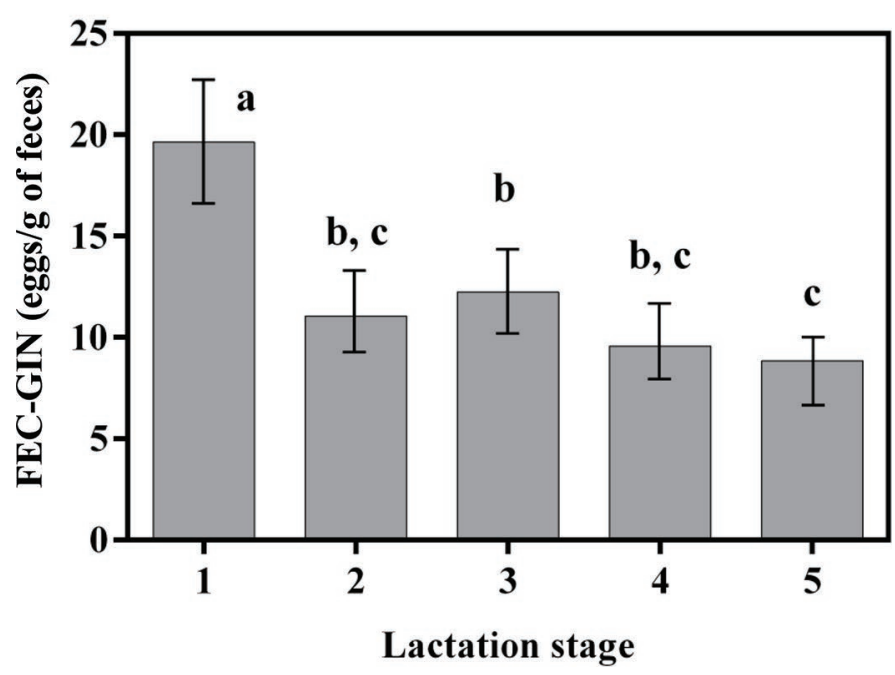

Figure 2. (A) Least squares means [model (1)] with corresponding SE for gastrointestinal nematode egg counts (FEC-GIN) for different parities. (B) Least squares means [model (1)] with corresponding SE for FEC-GIN for different lactation stages. Different letters $(\mathrm{a}-\mathrm{c})$ indicate significant differences $(P<0.05)$. Parity numbers 1 to 5 represent parities $1,2,3,4$, and $>4$, respectively; lactation stage was classified as 1: $\leq 14$ DIM, 2: 14-77 DIM, 3: 78-140 DIM, 4: 141-231 DIM, and 5: $\geq 2 \overline{32}$ DIM.

FLC-DV, SqrtFEC-GIN, SqrtFEC-FLU)] were quite stable with small standard errors (Table 6). Heritabilities from bivariate models with 2 endoparasite traits were almost identical with estimates from the RRTDM, including 1 endoparasite and 1 test-day production trait (not shown). The FEC-FLU was more heritable $(0.33 \pm 0.06)$ than FEC-GIN $(0.05-0.06 \pm 0.04)$ and FLC-DV (0.05 \pm 0.04; Table 6). Heritabilities from logtransformed (LogFEC-FLU) and square-rooted data (SqrtFEC-FLU) were even slightly higher $(0.39 \pm 0.06$ and $0.40 \pm 0.07$, respectively) than from the raw FECFLU data. For FLC-DV and FEC-GIN, heritabilities from log and square root transformations confirmed the low estimates from the original untransformed data. For the evaluation of endoparasite trait definitions, we compared Akaike information criteria from univariate RM [model 3] for the 3 endoparasite traits; Akaike information criterion values were always smallest for the untransformed data. Hence, the original untransformed endoparasite data set was used to infer genetic associations between endoparasite and milk production traits.

Genetic and Phenotypic Correlations Among Endoparasite Traits. The genetic correlation between FEC-GIN and FLC-DV was exactly 1.00, but close to zero between FEC-GIN and FEC-FLU $(-0.10)$ and close to zero between FLC-DV and FEC-FLU (0.03; Table 6). Standard errors for genetic correlations were quite high, but consistent genetic correlations were found when using log-transformed data in bivariate models. For SqrtFLC-DV and SqrtFEC-GIN, genetic correlations were slightly smaller than for untransformed or log-transformed data. Transformation of data had no effect on phenotypic correlations among endoparasite traits, which were close to zero in a range from -0.05 to $0.07( \pm 0.02)$.

Genetic Correlations Between Endoparasite and Milk Production Traits. Daily heritabilities from the RRTDM for all production traits across the whole lactation $(\mathrm{MY}=0.35-0.45 ;$ Pro\% $=0.05-0.51$; Fat $\%=0.33-0.65 ; \mathrm{FPR}=0.28-0.51 ; \mathrm{SCS}=0.14-0.22)$ were in a reasonable range. Variations of additive genetic variances and heritabilities by DIM indicate that different genes are switched on and off during lactation. Negative genetic correlations between MY and FLC-DV were observed during the whole lactation period (Figure 3). Genetic correlations between MY and FEC-FLU were negative until 215 DIM and changed to positive values in the later lactation stage at 220 DIM (Figure 3). Genetic correlations between MY and FECGIN were positive throughout, from 90 DIM to the end of lactation, with the largest correlation of 0.25 at 220 DIM (Figure 3). Both FEC-GIN and FEC-FLU were negatively correlated with Pro\% through the whole lactation period (Figure 4), whereas genetic correlations for Pro\% and FLC-DV were slightly negative between 40 and 220 DIM. A negative genetic correlation was also observed between Fat\% and FEC-GIN from 25 to 295 DIM (Figure 5). In contrast, Fat\% was positively correlated with FEC-FLU apart from the last lactation stage (Figure 5). The Fat\% was positively correlated with FLC-DV during the whole lactation (but close to zero between 135 to 185 DIM), with the highest genetic correlation of 0.58 at 365 DIM (Figure 5). Genetic correlation curves between FPR and endoparasite traits 


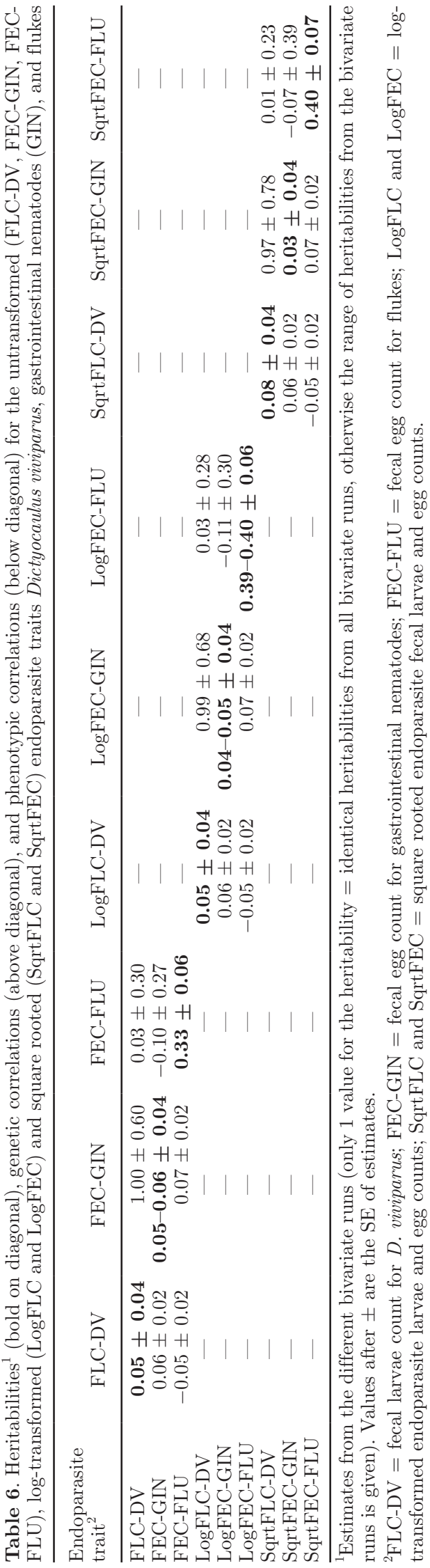

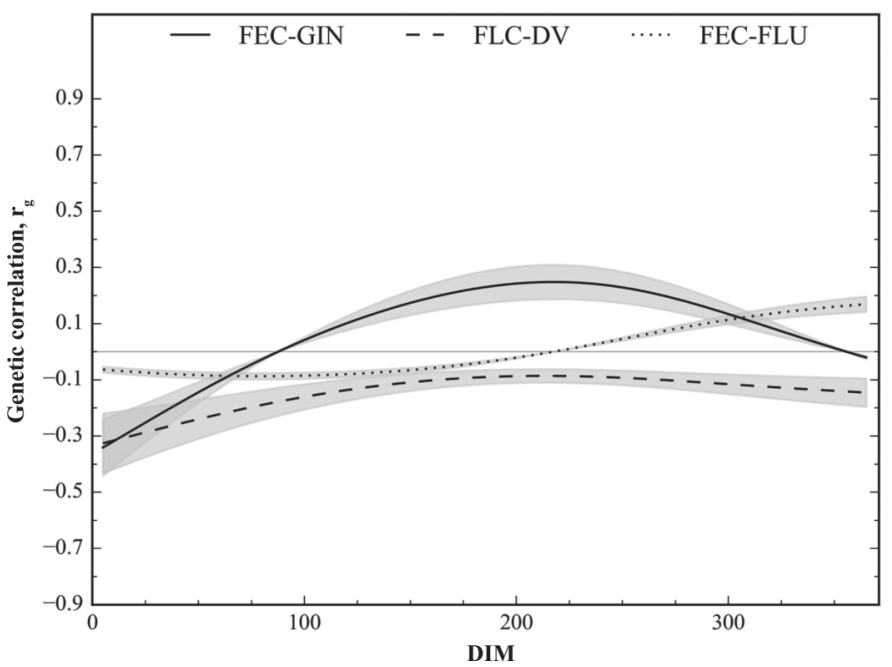

Figure 3. Daily genetic correlations with corresponding SE (gray areas) between the endoparasite traits fecal egg count for gastrointestinal nematodes (FEC-GIN), fecal larvae count for Dictyocaulus viviparus (FLC-DV), and fecal egg count for flukes (FEC-FLU) with test-day milk yield (MY).

(Figure 6) were quite similar compared with corresponding estimates for Fat\% endoparasite trait associations. Moderate genetic correlations throughout lactation in the range from 0.35 to 0.48 were identified between SCS and FEC-GIN (Figure 7). For the middle lactation period, genetic correlations were negative between SCS with FLC-DV, and negative throughout between SCS with FEC-FLU. Generally, the highest and lowest genetic correlations were found at the beginning and

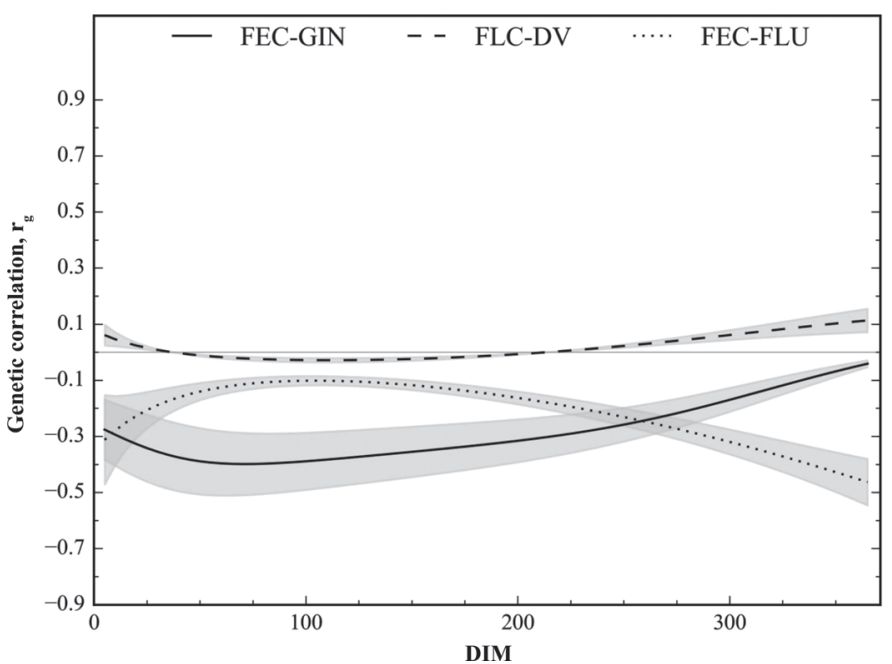

Figure 4. Daily genetic correlations with corresponding SE (gray areas) between the endoparasite traits fecal egg count for gastrointestinal nematodes (FEC-GIN), fecal larvae count for Dictyocaulus viviparus (FLC-DV), and fecal egg count for flukes (FEC-FLU) with test-day protein percentage (Pro\%). 


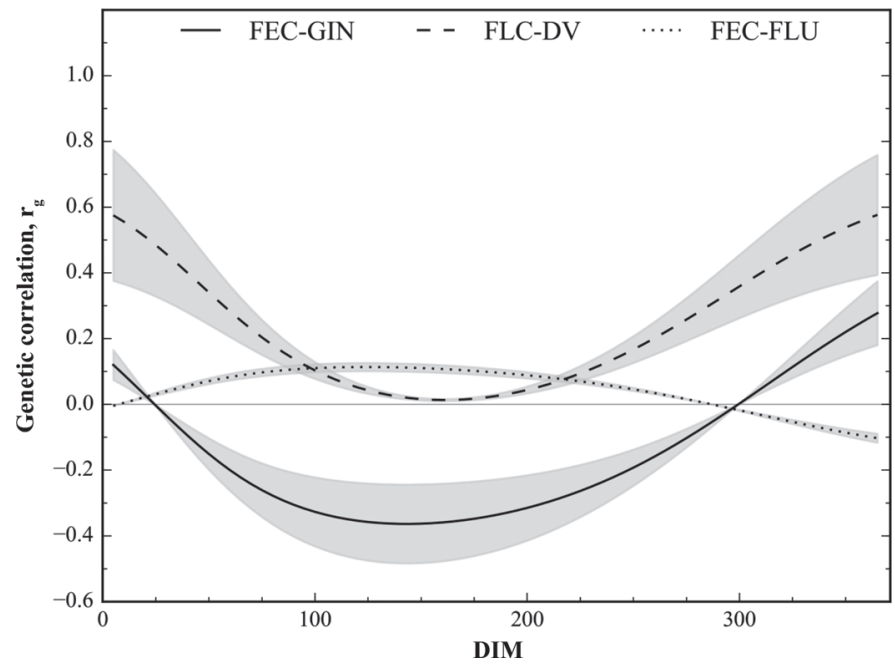

Figure 5. Daily genetic correlations with corresponding SE (gray areas) between the endoparasite traits fecal egg count for gastrointestinal nematodes (FEC-GIN), fecal larvae count for Dictyocaulus viviparus (FLC-DV), and fecal egg count for flukes (FEC-FLU) with test-day fat percentage (Fat\%).

the end of lactation period; however, standard errors were also largest at the extreme ends of the time scale.

\section{DISCUSSION}

\section{Genetic Line Comparisons}

Only a few studies addressed endoparasite infection comparisons between genetic lines or among cattle sub-

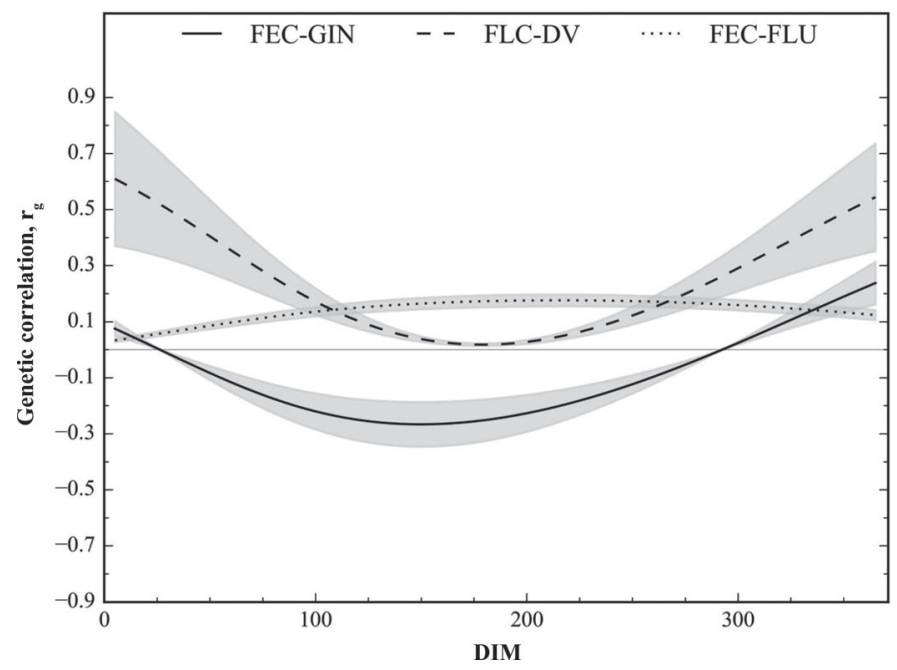

Figure 6. Daily genetic correlations with corresponding SE (gray areas) between the endoparasite traits fecal egg count for gastrointestinal nematodes (FEC-GIN), fecal larvae count for Dictyocaulus viviparus (FLC-DV), and fecal egg count for flukes (FEC-FLU) with fat-to-protein ratio (FPR). populations. Barlow and Piper (1985) observed significant intrabreed sire effects for endoparasite infections in Hereford, Simmental, Friesian, and Brahman cattle. For Dutch Friesian calves, Kloosterman et al. (1978) identified variation among sires regarding resistance to GIN. In the present study, the lowest susceptibility for GIN was identified for the HF-NZL line, reflecting the New Zealand breeding goal with a focus on adaptation to grazing systems (McCarthy et al., 2007). The HFNZL line was more resistant against GIN compared with the HF-GHm line, which has been bred and selected for indoor production systems over decades. In this regard, König et al. (2005a) identified genotype by environment interactions for production and functional traits when stratifying the HF-data set according to the production system characteristics indoor in east Germany versus grassland in west Germany. For novel functional traits (e.g., hock lesion score, BCS, lameness score, hygiene score), Brügemann et al. (2015) confirmed the superiority of HF-NZL over German Holstein selection lines. Knaus (2016) studied energy deficiency during lactation and identified an optimal BCS and energy balance in HF-NZL dairy cows, especially when comparing to high-yielding HF cows in grassland systems.

Collard et al. (2000) defined metabolic stress as response to a negative energy balance and as response to a quick mobilization of body fat depots in high-yielding dairy cows. Especially in the first third of lactation, metabolic stress caused metabolic disorders, but also increased susceptibility to other disease categories (claw disorders, fertility disorders, clinical mastitis;

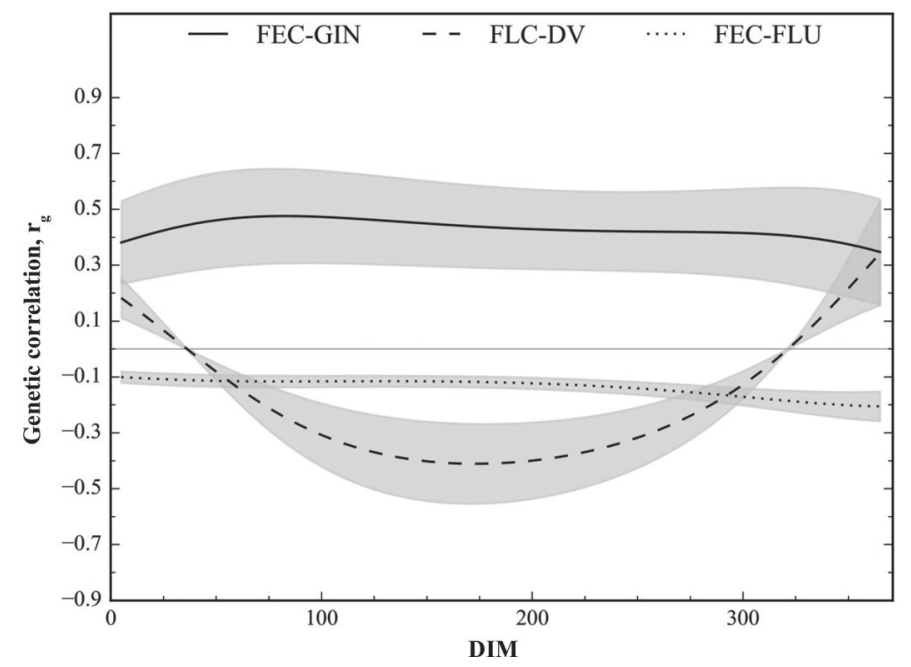

Figure 7. Daily genetic correlations with corresponding SE (gray areas) between the endoparasite traits fecal egg count for gastrointestinal nematodes (FEC-GIN), fecal larvae count for Dictyocaulus viviparus (FLC-DV), and fecal egg count for flukes (FEC-FLU) with SCS. 
Collard et al., 2000; Fleischer et al., 2001). In this context, König et al. (2005b) stated that "health problems appear to occur in clusters"; that is, a cow in a negative energy balance with increased SCS was also susceptible for claw disease infections. Hence, adaptive breeding for grassland systems with a focus on an optimal BCS might contribute to lower GIN prevalence rates, as observed in the HF-NZL line.

However, grazing systems in New Zealand differ from those in Germany, suggesting the implementation of specific selection lines being adapted to German grazing conditions. A first compromise in this regard was the creation of the HF-GHp line, based on German Holsteins with alternative breeding goals (i.e., strong weight on such breeding traits being important in NZL). In the present study and with regard to GIN infections, the HF-GHp line was competitive with HF-NZL.

Quite similar and highest LSM for FEC-GIN were identified for DSN and high-yielding Holstein cows (HF-GHm). A lower susceptibility with lower GIN egg excretion was expected for DSN, as DSN cattle have a long breeding history in the German grassland region of East Frisia, located at the coast of the federal state of Lower Saxony (Mügge et al., 1999). Utilizing a cross-classified research design with DSN and HF cows in the same herd, Al-Kanaan (2016) studied mechanisms of disease susceptibility in harsh environments. Al-Kanaan (2016) focused on physiological traits and found out that DSN cows were more susceptible to heat stress challenges compared with high-yielding HF. As a justification, the author described principles of selection theory as described by Via and Lande (1985); for example, reduced heat stress response might be due to lower phenotypic and genetic variations in intensively selected HF cows. A further explanation for higher prevalence rates in DSN cows addressed genetic analogy. In a comprehensive pedigree analysis, Jaeger et al. (2016) identified influential DSN sires not only from the East Frisia grassland region, but also from large-scale indoor herds in Berlin-Brandenburg, Germany. Artificial insemination DSN sires from the breeding organization of Berlin-Brandenburg were genetically closer related to the current DSN milking cow population compared with sires from western Germany grassland regions.

In the grassland outdoor production system, HFGHm cows (selected for indoor systems) acquired immunity against GIN infections because they had access to pasture during the heifer stage. Nevertheless, due to the pronounced selection strategy effect, infection rates were lower for HF-GHp. Generally, the immunity effect was proven in the present study. Our findings for highest GIN egg counts in primiparous cows are in agreement with results by Gasbarre et al. (2001), who identified a better immune response to GIN infections in later lactations. In contrast, other studies observed no effect of parity number on fecal egg counts for GIN (Agneessens et al., 2000; Borgsteede et al., 2000; Perri et al., 2011). Regarding the lactation stage, Perri et al. (2011) found highest FEC-GIN values around the time of calving and during the early lactation stage due to a lower immunity status as a result of metabolic stress.

In general, prevalence rates for GIN were higher for MIXED compared with purebred HF-NZL or HF-GHp cows. Because of the utilization of $100 \%$ of heterosis effects in $F_{1}$ crossbred cows, especially for low-heritability functional traits, lower prevalence rates were expected (Sørensen et al., 2008). Our finding corroborate with those by Suarez et al. (1995) in Argentina, who observed that purebred Angus cattle were more resistant against GIN than crossed Angus. In contrast, other authors reported a stronger endoparasite resistance in crossbred cattle compared with purebreds (O'Kelly, 1980; Peña et al., 2000; Oliveira et al., 2009).

\section{Heritabilities and Genetic and Phenotypic Correlations for Endoparasite Traits}

Regarding the most common endoparasite trait definitions, fecal egg counts were used to estimate genetic parameters for endoparasite resistance in ruminants (Barlow and Piper, 1985; Bryan and Kerr, 1989; Oliveira et al., 2009). In adult cattle, mostly zero-inflated data sets were databases for quantitative genetic studies because egg counts decrease with the host's aging due to acquired immunity. To cope with this statistical problem, and to achieve a Gaussian-like data distribution, previous studies applied logarithmic transformations of endoparasite fecal egg counts (Bisset et al., 1992; Zinsstag et al., 2000; Coppieters et al., 2009). Square root transformations for nematode egg counts were used by Bisset et al. (1992) and Woolaston et al. (1991). Heritability estimates for original and transformed data for different endoparasite species differed by approximately \pm 0.13 (Bisset et al., 1992), reflecting larger heritability estimate variations for different trait definitions than in the present study. Our heritability estimates for LogFEC-GIN and FEC-GIN (0.04-0.06) were in agreement with those by Coppieters et al. (2009) for log-transformed fecal egg counts (0.07-0.21) in Dutch Holstein-Friesian cows. In the present study, heritabilities for LogFLC-DVand FLC-DV (0.05) and for LogFEC-GIN and FEC-GIN (0.04-0.06) were small and very similar, reflecting that both endoparasites $(D$. viviparus and GIN) represent the same order, Strongylida. Low heritabilities for FEC-GIN and FLC-DV were due to a large environmental influence (i.e, large re- 
sidual variances for both traits). An even broader range of heritabilities of untransformed and transformed GIN fecal egg counts with low to moderate heritabilities in a range from 0.04 to 0.36 , as estimated in previous studies, is given in Table 1. Heritability estimate variations within same populations were due to research design configurations [e.g., artificial versus natural infections (Mugambi et al., 2005; Amarante et al., 2009), time and repetition of fecal sampling (Zinsstag et al., 2000), and animal age (Kornaś et al., 2015; Passafaro et al., 2015)]. In contrast to our study, most previous studies estimated genetic parameters for GIN in calves or heifers (Kloosterman et al., 1978; Gasbarre et al., 1990), or in beef cattle populations (Morris and Amyes, 2012). Genetic statistical modeling for lactating cows differed from those for calves or beef cattle because parity and lactation stage has to be taken into account (Coppieters et al., 2009; Perri et al., 2011).

Due to the larger additive-genetic and the lower residual component (not shown), the heritability for FEC-FLU was substantially larger (0.33) compared with FEC-GIN (0.05-0.06) and FLC-DV (0.05). For dairy and beef cattle in Ireland grassland systems, McClure et al. (2014) used a binary trait definition and estimated a lower heritability of 0.15 for the presence of liver flukes (F. hepatica). Twomey et al. (2016) reported a smaller heritability, in the range from 0.01 and 0.09 , for the binary traits liver damage caused by $F$. hepatica and antibody response to $F$. hepatica in Irish dairy and beef cattle. Threshold models for categorical endoparasite traits with 2 or more classes were also applied by Passafaro et al. (2015). Passafaro et al. (2015) compared heritabilities for endoparasite traits from both linear and threshold models, but differences in heritability estimates from both models were not significant.

The pronounced positive genetic relationship (1.00) between FEC-GIN and FLC-DV simplifies selection strategies. Selection on improved resistance against GIN implies associated infection resistance against $D$. viviparus and vice versa. This phenomenon was emphasized in previous studies in sheep (Woolaston and Eady, 1995; Gray, 1997), where a higher resistance to Haemonchus contortus was accompanied with lower egg counts for other GIN species. In the present study, the phenotypic correlation between FLC-DV and FEC-GIN was also positive but close to zero. Accordingly, Morris et al. (2003) compared genetic and phenotypic correlations for different GIN species by using log-transformed fecal egg counts and endoparasite antibody traits in 2 calf-crops of Angus cattle. They identified large genetic correlations among all endoparasite traits, whereas phenotypic correlations between fecal egg counts and endoparasite antibody traits were substantially lower.

\section{Genetic Correlations Between Endoparasite Traits with Milk Production Traits}

According to the genetic correlation estimates from the present study, breeding for increasing milk yield at the beginning of lactation will decrease genetic susceptibility to endoparasite infections (D. viviparus, GIN, and F . hepatica). Conversely, susceptibility to endoparasite infections at the genetic scale is associated with a lower milk production level. Explanations for strong genetic correlations between endoparasite infections and milk productivity could be due to pleiotropic effects or due to linkage, suggesting ongoing genomic analyses based on dense high-throughput SNP marker data. Our results for quantitative genetic relationships are in contrast to most of the previous studies conducted at phenotypic scales (Barger, 1993; Sordillo et al., 2009; Perri et al., 2011), where energy deficiency combined with metabolic diseases during the onset of lactation impaired the immune system, making highyielding cows more susceptible to GIN infections. The genetic correlation close to zero between MY and the endoparasite trait FEC-FLU indicates that breeding and selection on resistance to $F$. hepatica improves disease resistance without reducing productivity in grazing herds. Apart from the late lactation stage, genetic correlations between Fat\% and FEC-FLU were positive. For FLC-DV, a positive genetic correlation with Fat\% was found during the whole lactation. A possible explanation addresses the naturally genetically antagonistic relationship between Fat\% and MY (Collard et al., 2000; Yin et al., 2012).

The shape of genetic correlation curves with FLCDV, FEC-GIN, and FEC-FLU were similar for Fat\% and FPR. A high FPR early in lactation, especially due to high Fat\%, indicates energy deficiency and metabolic stress (Buttchereit et al., 2011). As outlined at the phenotypic scale, cows in a pronounced negative energy balance mobilize their body fat depots too quickly, contributing to disease susceptibility at the beginning of lactation (Lassen et al., 2003); this was shown in the present study for $D$. viviparus and flukes via genetic relationships with FPR.

Protein content was genetically negatively correlated with FEC-GIN and FEC-FLU during the whole lactation. Genetic correlations between Pro\% and FLC-DV were close to zero. This outcome is in contrast to Afolayan et al. (2009), who found a positive genetic correlation (0.42) between Pro\% and worm egg counts in ewes, reflecting different genetic mechanisms in different species (Barillet, 2007; Bishop and Morris, 2007) or effect of selection (Veerkamp et al., 2003; Haenlein, 2007). Another explanation for different findings addresses 
statistical modeling of longitudinal data; Afolayan et al. (2009) used cubic splines, but we used Legendre polynomials for the modeling of the lactation curve.

Positive genetic correlations between FEC-GIN and SCS are in agreement with estimates in dairy sheep (Sechi et al., 2009), indicating that the same cows are genetically susceptible for both udder and endoparasite infections. A physiological explanation for this relationship might be that infections with GIN increased gastrointestinal permeability (McKellar, 1993), resulting in a migration of other pathogens in the bloodstream and in the udder. So far, such pathogenic mechanisms have not been identified for D. viviparus and F. hepatica. For FEC-FLU (genetic negative correlation with SCS), we hypothesized that an increase of somatic cells in the milk was due to the host immune response. Our hypothesis was based on findings by Molina-Hernández et al. (2015), who found that an infection with $F$. hepatica depressed initiation of an immune response, probably resulting in a lower SCS.

In the present study, daily genetic correlations from the RRTDM between FEC-GIN and FLC-DV with test-day production traits were more extreme at the beginning and at the end of lactation. In comparison for FEC-FLU, the shape of the genetic correlation curves was more consistent during lactation, and corresponding standard errors were smaller. Our finding of inflated genetic correlations for the low heritability traits FEC-GIN and FLC-DV at the extreme ends of the continuous scale correspond with accuracies of random regression results for functional energy efficiency or fertility traits (Ravagnolo and Misztal, 2002; Buttchereit et al., 2011).

\section{CONCLUSIONS}

In conclusion, infections with the endoparasites $D$. viviparus and GIN differed in Black and White cattle selection lines. Lowest and similar infection rates for GIN were identified for the HF-NZL and the HF-GHp line, reflecting better adaptation of grassland selection lines to grassland systems. The transformation of endoparasite data had no effect on genetic parameters estimates (i.e., genetic parameters were almost identical for the original data, log-transformations, and square rooted data). The moderate heritability estimate of 0.33 for FEC-FLU indicates substantial genetic variation for $F$. hepatica in selected lines of Black and White cattle, which can be used for breeding on disease resistance in overall dairy cattle breeding goals. Negative genetic correlations (desired in terms of breeding) between the most important production traits, MY and Pro\%, with endoparasite traits allow genetic progress in both trait categories simultaneously.

\section{ACKNOWLEDGMENTS}

The authors thank the Federal Ministry for Food and Agriculture (Bonn, Germany) for providing the Grant (no. 12NA035) supporting the research project 'economic evaluation of breeding strategies in pasture-based production systems to improve animal health and animal welfare' within the framework of the Federal Program of Organic Farming and Other Forms of Sustainable Agriculture. The authors thank Karin Rübesam (University of Kassel, Germany), Maria Jaeger (University of Gießen, Germany), Jennifer Hofmann (University of Veterinary Medicine Hannover, Germany), and Solveig Peurois (Sabine Blindow School, Germany) for technical support. We gratefully thank the H. Wilhelm Schaumann Stiftung for the provision of a $\mathrm{PhD}$ grant to K. May.

\section{REFERENCES}

Afolayan, R. A., N. M. Fogarty, J. E. Morgan, G. M. Gaunt, L. J. Cummins, and A. R. Gilmour. 2009. Preliminary genetic correlations of milk production and milk composition with reproduction, growth, wool traits and worm resistance in crossbred ewes. Small Rumin. Res. 82:27-33.

Agneessens, J., E. Clearebout, P. Dorny, F. H. M. Borgsteede, and J. Vercruysse. 2000. Nematode parasitism in adult dairy cows in Belgium. Vet. Parasitol. 90:83-92.

Al-Kanaan, A. 2016. Heat stress response for physiological traits in dairy and dual purpose cattle populations on phenotypic and genetic scales. PhD thesis, Faculty of Organic Agriculture, University of Kassel, Kassel, Germany.

Ali, A. K. A., and G. E. Shook. 1980. An optimum transformation for somatic cell concentration in milk. J. Dairy Sci. 63:487-490.

Amarante, A. F. T., I. Susin, R. A. Rocha, M. B. Silva, C. Q. Mendes, and A. V. Pires. 2009. Resistance of Santa Ines and crossbred ewes to naturally acquired gastrointestinal nematode infections. Vet. Parasitol. 165:273-280.

Baermann, G. 1917. Eine einfache Methode zur Auffindung von Ankylostomum (Nematoden)-Larven in Erdproben. A simple method for isolation of Ancylostoma (nematode) larvae in soil samples. Geneeskundig Tijdschrift voor Nederlandsch-Indië 57:131-137.

Barger, I. A. 1993. Influence of sex and reproductive status on susceptibility of ruminants to nematode parasitism. Int. J. Parasitol. 23:463-469.

Barillet, F. 2007. Genetic improvement for dairy production in sheep and goats. Small Rumin. Res. 70:60-75.

Barlow, R., and L. R. Piper. 1985. Genetic analyses of nematode egg counts in Hereford and crossbred Hereford cattle in the subtropics of New South Wales. Livest. Prod. Sci. 12:79-84.

Bishop, S. C., F. Jackson, R. L. Coop, and M. J. Stear. 2004. Genetic parameters for resistance to nematode infections in Texel lambs and their utility in breeding programmes. Anim. Sci. 78:185-194.

Bishop, S. C., and C. A. Morris. 2007. Genetics of disease resistance in sheep and goats. Small Rumin. Res. 70:48-59.

Bisset, S. A. 1994. Helminth parasites of economic importance in cattle in New Zealand. N.Z. J. Zool. 21:9-22.

Bisset, S. A., A. Vlassoff, C. A. Morris, B. R. Southey, R. L. Baker, and A. G. H. Parker. 1992. Heritability of and genetic correlations among faecal egg counts and productivity traits in Romney sheep. N. Z. J. Agric. Res. 35:51-58.

Bohmanova, J., F. Miglior, J. Jamrozik, I. Misztal, and P. G. Sullivan. 2008. Comparison of random regression models with Legendre polynomials and linear splines for production traits and somatic cell score of Canadian Holstein cows. J. Dairy Sci. 91:3627-3638. 
BÖLW (Bund Ökologische Landwirtschaft). 2016. Zahlen, Daten, Fakten: Die Biol.-Branche. Accessed Jan. 12, 2017. http://www.boelw. de/themen/zahlendatenfakten/.

Borgsteede, F. H. M., J. Tibben, J. B. W. J. Cornelissen, J. Agnessens, and C. P. H. Gaasenbeek. 2000. Nematode parasites of adult dairy cattle in the Netherlands. Vet. Parasitol. 89:287-296.

Bouix, J., J. Krupinski, R. Rzepecki, B. Nowosad, I. Skrzyzala, M. Roborzynski, W. Fudalewicz-Niemczyk, M. Skalska, A. Malczewski, and L. Gruner. 1998. Genetic resistance to gastrointestinal nematode parasites in Polish long-wool sheep. Int. J. Parasitol. 28:1797-1804.

Brügemann, K., K. Rübesam, E. Leisen, and S. König. 2015. Genotypenvergleich im Hinblick auf Merkmale des Wohlbefindens in Milchviehbetrieben mit Schwerpunkt Weidehaltung. Accessed Nov. 23, 2016. http://orgprints.org/view/projects/int-conf-wita-2015. html

Bryan, R. P., and J. D. Kerr. 1989. The relation between the natural worm burden of steers and the faecal egg count differentiated to species. Vet. Parasitol. 30:327-334.

Burrow, H. M. 2001. Variances and covariances between productive and adaptive traits and temperament in a composite breed of tropical beef cattle. Livest. Prod. Sci. 70:213-233.

Buttchereit, N., E. Stamer, W. Junge, and G. Thaller. 2011. Short communication: Genetic relationships among daily energy balance, feed intake, body condition score, and fat to protein ratio of milk in dairy cows. J. Dairy Sci. 94:1586-1591.

Charlier, J., E. Claerebout, L. Duchateau, and J. Vercruysse. 2005. A survey to determine relationships between bulk tank milk antibodies against Ostertagia ostertagi and milk production parameters. Vet. Parasitol. 129:67-75.

Charlier, J., J. Höglund, G. von Samson-Himmelstjerna, P. Dorny, and J. Vercruysse. 2009. Gastrointestinal nematode infections in adult dairy cattle: Impact on production, diagnosis and control. Vet. Parasitol. 164:70-79.

Collard, B. L., P. J. Boettcher, J. C. M. Dekkers, D. Petitclerc, and L. R. Schaeffer. 2000. Relationships between energy balance and health traits of dairy cattle in early lactation. J. Dairy Sci. 83:2683-2690.

Coppieters, W., T. H. M. Mes, T. Druet, F. Farnir, N. Tamma, C. Schrooten, A. W. C. A. Cornelissen, M. Georges, and H. W. Ploeger. 2009. Mapping QTL influencing gastrointestinal nematode burden in Dutch Holstein-Friesian dairy cattle. BMC Genomics 10:96.

Dank, M., M. Holzhauer, A. Veldhuis, and K. Frankena. 2015. Association between Dictyocaulus viviparus status and milk production parameters in Dutch dairy herds. J. Dairy Sci. 98:7741-7747.

Eady, S. J., R. R. Woolaston, R. P. Lewer, H. W. Raadsma, A. A. Swan, and R. W. Ponzoni. 1998. Resistance to nematode parasites in Merino sheep: Correlation with production traits. Aust. J. Agric. Res. 49:1201-1211.

Fischer, T. M., A. R. Gilmour, and J. H. J. van der Werf. 2004. Computing approximate standard errors for genetic parameters derived from random regression models fitted by average information REML. Genet. Sel. Evol. 36:363-369.

Fleischer, P.. M. Metzner, M. Beyerbach, M. Hoedemaker, and W. Klee. 2001. The relationship between milk yield and the incidence of some diseases in dairy cows. J. Dairy Sci. 84:2025-2035.

Gasbarre, L. C., E. A. Leighton, and C. J. Davies. 1990. Genetic control of immunity to gastrointestinal nematodes of cattle. Vet. Parasitol. 37:257-272.

Gasbarre, L. C., E. A. Leighton, and T. Sonstegard. 2001. Role of the bovine immune system and genome in resistance to gastrointestinal nematodes. Vet. Parasitol. 98:51-64.

Gray, G. D. 1997. The use of genetically resistant sheep to control nematode parasitism. Vet. Parasitol. 72:345-357.

Haenlein, G. F. W. 2007. About the evolution of goat and sheep milk production. Small Rumin. Res. 68:3-6.

Holzhauer, M., G. van Schaik, H. W. Saatkamp, and H. W. Ploeger. 2011. Lungworm outbreaks in adult dairy cows: estimating economic losses and lessons to be learned. Vet. Rec. 169:494.

Huth, F. 1995. Laktation des Rindes. Verlag Eugen Ulmer, Stuttgart, Germany.
Jackson, R. 2016. Multi-state modelling with R: The msn package. MRC Biostatistics Unit, Cambridge, UK. Accessed May 17, 2017. https://cran.r-project.org/web/packages/msm/vignettes/msmmanual.pdf.

Jaeger, M., K. Brügemann, and S. König. 2016. Genetic relationships and trait comparison between and within lines of local dual purpose cattle; 67th Annual Meeting of the European Association for Animal Production, Belfast, Ireland. August 29-September 4, 2016. Wageningen Academic Publishers, Wageningen, the Netherlands.

Kaplan, R. M. 2001. Fasciola hepatica: A review of economic impact in cattle and considerations for control. Vet. Ther. 2:40-50.

Kloosterman, A., G. A. A. Albers, and R. van den Brink. 1978. Genetic variation among calves in resistance to nematode parasites. Vet. Parasitol. 4:353-368.

Kloosterman, A., H. K. Parmentier, and H. W. Ploeger. 1992. Breeding cattle and sheep for resistance to gastrointestinal nematodes. Parasitol. Today 8:330-335.

Knaus, W. 2016. Perspectives on pasture versus indoor feeding of dairy cows. J. Sci. Food Agric. 96:9-17.

Knubben-Schweizer, G., P. Deplazes, P. R. Torgerson, C. Rapsch, M. L. Meli, and U. Braun. 2010. Bovine fasciolosis in Switzerland: Relevance and control. Schweiz. Arch. Tierheilkd. 152:223-229.

König, S., G. Dietl, I. Raeder, and H. H. Swalve. 2005a. Genetic relationships between dairy performance under large-Scale farm and family farm conditions. J. Dairy Sci. 88:4087-4096.

König, S., R. Sharifi, H. Wentrot, D. Landmann, M. Eise, and H. Simianer. 2005b. Genetic parameters of claw and foot disorders estimated with logistic models. J. Dairy Sci. 88:3316-3325.

Kornaś, S., G. Sallé, M. Skalska, I. David, A. Ricard, and J. Cabaret. 2015. Estimation of genetic parameters for resistance to gastrointestinal nematodes in pure blood Arabian horses. Int. J. Parasitol. 45:237-242.

Kuerpick, B., F. J. Conraths, C. Staubach, A. Fröhlich, T. Schnieder, and C. Strube. 2013. Seroprevalence and GIS-supported risk factor analysis of Fasciola hepatica infections in dairy herds in Germany. Parasitology 140:1051-1060.

Lassen, J., M. Hansen, M. K. Sørensen, G. P. Aamand, L. G. Christensen, and P. Madsen. 2003. Genetic relationships between body condition score, dairy character, mastitis, and diseases other than mastitis in first-parity Danish Holstein cows. J. Dairy Sci. 86:3730-3735.

Leighton, E. A., K. D. Murrell, and L. C. Gasbarre. 1989. Evidence for genetic control of nematode egg-shedding rates in calves. J. Parasitol. 75:498-504.

Lynch, M., and B. Walsh. 1998. Genetics and Analysis of Quantitative Traits. Sinauer, Sunderland, MA

Mackinnon, M. J., K. Meyer, and D. J. S. Hetzel. 1991. Genetic variation and covariation for growth, parasite resistance and heat tolerance in tropical cattle. Livest. Prod. Sci. 27:105-122.

Madsen, P., and J. Jensen. 2013. A user's guide to DMU. A package for analysing multivariate mixed models. Version 6 , release 5.2. Center for quantitative genetics and genomics. Dept. of Molecular Biology and Genetics, University of Aarhus, Research Centre Foulum. Tjele, Denmark

McCarthy, S., B. Horan, P. Dillon, P. O'Connor, M. Rath, and L. Shalloo. 2007. Economic comparison of divergent strains of Holstein-Friesian cows in various pasture-based production systems. J. Dairy Sci. 90:1493-1505.

McClure, J., A. R. Cromie, R. Sayers, D. Graham, N. Byrne, and D. P. Berry. 2014. Genetics of susceptibility to bovine diarrhea virus, bovine herpesvirus type 1 and Fasciola hepatica in cattle. Proceedings of the 10th World Congress of Genetics Applied to Livestock Production. ASAS, Vancouver, BC, Canada.

McKellar, Q. A. 1993. Interactions of Ostertagia species with their bovine and ovine host. Int. J. Parasitol. 23:451-462.

McMahon, C., D. J. Bartley, H. W. J. Edgar, S. E. Ellison, J. P. Barley, F. E. Malone, R. E. B. Hanna, G. P. Brennan, and I. Fairweather. 2013. Anthelmintic resistance in Northern Ireland (I) Prevalence of resistance in ovine gastrointestinal nematodes, as 
determined through faecal egg count reduction testing. Vet. Parasitol. 195:122-130.

Miglior, F., B. L. Muir, and B. J. van Doormaal. 2005. Selection indices in Holstein cattle of various countries. J. Dairy Sci. 88:1255-1263.

Molina-Hernández, V., G. Mulcahy, J. Pérez, Á. Martínez-Moreno, S. Donnelly, S. M. O'Neill, J. P. Dalton, and K. Cwiklinski. 2015. Fasciola hepatica: We may not be there yet but we're on the right road. Vet. Parasitol. 208:101-111.

Moll, L., C. P. H. Gaasenbeek, P. Vellema, and F. H. M. Borgsteede. 2000. Resistance of Fasciola hepatica in cattle and sheep in the Netherlands. Vet. Parasitol. 91:153-158.

Morris, C. A., and N. C. Amyes. 2012. Heritability and repeatability of resistance to nematode parasites in commercial beef cattle. Proc. N.Z. Soc. Anim. Prod. 72:236-239.

Morris, C. A., R. S. Green, N. G. Cullen, and S. M. Hickey. 2003. Genetic and phenotypic relationships among faecal egg count, antinematode antibody level and live weght in Angus cattle. Anim. Sci. $76: 167-174$

Morris, C. A., M. Wheeler, B. C. Hosking, T. G. A. Watson, P. Hurford, B. J. Foote, and J. F. Foote. 1997. Genetic parameters for milk yield and faecal nematode egg count in Saanen does. N. Z. J. Agric. Res. 40:523-528.

Mugambi, J. M., J. O. Audho, S. Njomo, and R. L. Baker. 2005. Evaluation of the phenotypic performance of a Red Maasai and Dorper double back-cross resource population: indoor trickle challange with Haemonchus contortus. Vet. Parasitol. 127:263-275.

Mügge, B., W. E. Lutz, H. Südbeck, and S. Zelfel. 1999. Deutsche Holsteins: Die Geschichte einer Zucht. Verlag Eugen Ulmer, Stuttgart, Germany.

O'Kelly, J. C. 1980. Parasitism and blood composition in genetically different types of cattle grazing in a tropical environment. Vet. Parasitol. 6:381-390.

Oliveira, M. C. S., M. M. Alencar, A. C. S. Chagas, R. Giglioti, and N. H. Oliveira. 2009. Gastrointestinal nematode infection in beef cattle of different genetic groups in Brazil. Vet. Parasitol. 166:249254 .

Passafaro, T. L., J. P. B. Carrera, L. L. dos Santos, F. S. S. Raidan, D. C. C. dos Santos, E. P. Cardoso, R. C. Leite, and F. L. B. Toral. 2015. Genetic analysis of resistance to ticks, gastrointestinal nematodes and Eimeria spp. in Nellore cattle. Vet. Parasitol. 210:224-234.

Peña, M. T., J. E. Miller, W. Wyatt, and M. T. Kearney. 2000. Differences in susceptibility to gastrointestinal nematode infection between Angus and Brangus cattle in south Louisiana. Vet. Parasitol. 89:51-61.

Perri, A. F., M. E. Mejía, N. Licoff, L. Lazaro, M. Miglierina, A. Ornstein, D. Becu-Villalobos, and I. M. Lacau-Mengido. 2011. Gastrointestinal parasites presence during peripartum decreases total milk production in grazing dairy Holstein cows. Vet. Parasitol. 178:311-318.

Piccand, V., E. Cutullic, S. Meier, F. Schori, P. L. Kunz, J. R. Roche, and P. Thomet. 2013. Production and reproduction of Fleckvieh, Brown Swiss, and 2 strains of Holstein-Friesian cows in a pasturebased, seasonal-calving dairy system. J. Dairy Sci. 96:5352-5363.

Ploeger, H. W., and A. Kloosterman. 1993. Gastrointestinal nematode infections and weight in dairy replacement stock: first-year calves. Vet. Parasitol. 46:223-241.

R Core Team. 2013. R: A language and environment for statistical computing, R Core Team, Vienna, Austria.

Ravagnolo, O., and I. Misztal. 2002. Effect of heat stress on nonreturn rate in Holstein cows: Genetic analyses. J. Dairy Sci. 85:3092-3100.

Schnieder, T., A. Bellmer, and A. M. Tenter. 1993. Seroepidemiological study on Dictyocaulus viviparus infections in first year grazing cattle in northern Germany. Vet. Parasitol. 47:289-300.
Schunn, A. M., F. J. Conraths, C. Staubach, A. Fröhlich, A. Forbes, T. Schnieder, and C. Strube. 2013. Lungworm infections in German dairy cattle herds-Seroprevalence and GIS-supported risk factor analysis. PLoS One 8:e74429.

Sechi, S., S. Salaris, A. Scala, R. Rupp, C. Moreno, S. C. Bishop, and S. Casu. 2009. Estimation of (co)variance components of nematode parasites resistance and somatic cell count in dairy sheep. Ital. J. Anim. Sci. 8:156-158.

Seifert, G. W. 1977. The genetics of helminth resistance in cattle Pages 4-8 in 3rd Int. Cong. Of the Soc. for the Advancement of Breeding Researches in Asia and Oceania. Canberra, Australia. Vol. 7. SABRAO, Canberra, Australia.

Silva, B. F., C. C. Bassetto, R. J. Shaw, A. M. O. Canavessi, and A. F. T. Amarante. 2012. Parasitism by Oestrus ovis: Influence of sheep breed and nematode infections. Vet. Parasitol. 186:437-444.

Sordillo, L. M., G. A. Contreras, and S. L. Aitken. 2009. Metabolic factors affecting the inflammatory response of periparturient dairy cows. Anim. Health Res. Rev. 10:53-63.

Sørensen, M. K., E. Norberg, J. Pedersen, and L. G. Christensen. 2008. Invited review: Crossbreeding in dairy cattle: A Danish perspective. J. Dairy Sci. 91:4116-4128.

Suarez, V. H., M. R. Busetto, and R. M. Lorenzo. 1995. Comparative effects of nematode infection on Bos taurus and Bos indicus crossbred calves grazing on Argentina's Western Pampas. Vet. Parasitol. 58:263-271.

Suarez, V. H., O. E. Ciminari, D. O. Bedotti, M. R. Busetti, and E. M. Bello. 1990. Epidemiology, effects and control of nematode infections on Zebu Crossbred, Hereford and Hereford x Brahman calves of argentina's western pampas. Vet. Parasitol. 35:79-91.

Thienpont, D., F. Rochette, and O. F. J. Vanparijs. 1979. Diagnosing Helminthiasis by Coprological Examination. Janssen Research Foundation, Beerse, Belgium.

Twomey, A. J., R. G. Sayers, R. I. Carroll, N. Byre, E. O'Brien, M. L. Doherty, J. C. McClure, D. A. Graham, and D. P. Berry. 2016. Genetic parameters for both a liver damage phenotype caused by Fasciola hepatica and antibody response to Fasciola hepatica phenotype in dairy and beef cattle. J. Anim. Sci. 94:4109-4119.

Veerkamp, R. F., B. Beerda, and T. Van der Lende. 2003. Effects of genetic selection for milk yield on energy balance, levels of hormones, and metabolites in lactating cattle, and possible links to reduced fertility. Livest. Prod. Sci. 83:257-275.

Via, S., and R. Lande. 1985. Genotype-environment interaction and the evolution of phenotypic plasticity. Evolution 39:505-522.

Woolaston, R. R., and S. J. Eady. 1995. Australian research on genetic resistance to nematode parasites. Pages 1-12 in Breeding for Resistance to Infectious Diseases in Small Ruminants. D. G. Gray, R. R. Woolaston, and B. Eaton, ed Australian Centre of International Agricultural Research, Canberra, Australia.

Woolaston, R. R., R. G. Windon, and G. D. Gray. 1991. Genetic variation in restistance to internal parasites in Armidale experimental flocks. Pages 1-9 in Breeding for disease resistance in sheep. G. D. Gray, and R. R. Woolaston, ed. Australian Wool Corporation, Melbourne.

Yin, T., B. Bapst, U. U. von Borstel, H. Simianer, and S. König. 2012. Genetic parameters for Gaussian and categorical traits in organic and low input dairy cattle herds based on random regression methology. Livest. Sci. 147:159-169.

Zinsstag, J., P. Ankers, M. Njie, T. Smith, V. S. Pandey, K. Pfister, and M. Tanner. 2000. Heritability of gastrointestinal nematode faecal egg counts in West African village N'Dama cattle and its relation to age. Vet. Parasitol. 89:71-78. 